\title{
A Risk Management Tool or an Investment Strategy? Understanding the Unstable Farm Insurance Demand via a Gain-Loss Framework
}

\author{
Ying (Jessica) Cao, Alfons Weersink, and Emma Ferner
}

\begin{abstract}
Risk management tools are at the core of farm policy in many developed countries, and their effectiveness relies on the appropriate mechanism design. This study developed a gain-loss framework based on prospect theory to examine the reasons for the declining use of the main risk management tool offered to farmers despite growing volatility in returns. Using the administrative Ontario Farm Income Database (OFID) 2003 to 2013 and taking the beef sector as the example, this study found that the gain-loss framework predicts and explains the dynamic program participation pattern better than the conventional expected utility framework. Farms were found to be more likely to stay enrolled in the program when they experienced either larger gains or losses in revenue compared to previous years, suggesting that they were using the insurance programs both as an investment strategy (to seek government subsidies) and as a risk management tool (to protect against business risks), though the effects of revenue losses and hence risk management needs were stronger than gains. In addition, the program payment history and farm characteristics also shape the dynamic participation patterns. The findings increased the understanding of the drivers of withdrawal behavior associated with government-sponsored business risk management programs.
\end{abstract}

Key Words: insurance, prospect theory, reference point, risk management

Risk management is at the core of agricultural policy for many countries due to the inherent yield and price risk within the sector and the incompleteness of private insurance markets (Stiglitz 1987). In the United States, the Federal Crop Insurance Act of 1980 replaced disaster assistance and was based on actuarial soundness, with private companies marketing insurance plans at highly subsidized rates (Goodwin 1993). Changes in the 2014 US Farm Bill included more options for price and production coverage levels in the risk management-based support programs, but farmers are not fully satisfied with their enrollment decisions and suggest future changes to the program in the

Ying (Jessica) Cao, Division of Health Services Policy and Practice, State University of New York at Buffalo, NY, USA. Alfons Weersink and Emma Ferner, Department of Food, Agricultural and Resource Economics, University of Guelph, ON, Canada. Correspondence: Ying (Jessica) Cao, Division of Health Services Policy and Practice - State University of New York at Buffalo = NY " USA - Phone: +1(716)829-5369 - Email ycao25@buffalo.edu

The authors would like to thank the Ontario Ministry of Agriculture, Food and Rural Affairs (OMAFRA) and University of Guelph Partnership Program for funding support (\#030047).

Agricultural and Resource Economics Review 49/3 (December 2020) 410-436

(C) The Author(s) 2019. This is an Open Access article, distributed under the terms of the Creative

Commons Attribution licence (http://creativecommons.org/licenses/by/4.0/), which permits unrestricted re-use, distribution, and reproduction in any medium, provided the original work is 
next Farm Bill (Taylor et al. 2017). In Europe, member states tend to adopt individual agricultural risk management policies in the form of crop insurance subsides or agricultural solidarity funds (Santeramo et al. 2016). In Canada, risk management programs offered by government moved away from price and yield stabilization mechanisms toward individual, income-based whole-farm insurance in the 1990s (Chen and Meilke 1996). The primary tool within the current suite of Business Risk Management (BRM) programs is AgriStability, which is a whole-farm revenue insurance program that protects net income based on a historical reference margin. The program is funded through support of the federal and provincial governments, with producers paying a program fee of approximately $\$ 450$ per $\$ 100,000$ of margin coverage (AAFC 2013).

Despite the subsidization of the program by both federal and provincial governments, participation in AgriStability has declined over time. For example, the percentage of farmers enrolled in Agri-Stability has fallen from approximately 75 percent to less than 50 percent between 2003 and 2013 . Delays in receiving program payments and changes to fundamental aspects of the program, including coverage levels and premiums, have been mentioned as contributing causes of the phenomenon but are without empirical validation (Poon 2013). The declining participation of the risk management program despite growing variability in income implies greater understanding of the farmer decision-making process is required.

Previous studies on the determinants of insurance adoption have typically assumed producers maximize their expected utility of profits subject to any constraint that affects the distribution of profits, including characteristics of their marketing and production environment and risk attitudes. Early studies found the cost of premiums decreases the demand for insurance (Niewuwoudt et al. 1985; Goodwin 1993), but more recent studies found farmers' insurance decisions are not sensitive to the level of premiums (Smith and Baquet 1996; Garrido and Zilberman 2007; Enjolras and Sentis 2011). Cabas, Leiva, and Weersink (2008) found that the effect of premium rates for overall participation was not statistically significant, but when participation was modelled as separate entry and exit decisions, an increase in the premium rate decreased the number of entries from the program and increased the number of exits. Larger farms are more likely to insure due potentially to the ability to handle the administrative requirements of the program (Mishra and Goodwin 2003; Sherrick et al. 2004; Lefebvre et al. 2014; Uzea et al. 2014a, 2014b). Farms facing higher risk exposure are more likely to insure (Coble et al. 1996; Lefebvre et al. 2014), while those with the ability to reduce risk either through off-farm employment or diversification are less likely to insure (Pennings et al. 2008; Velandia et al. 2009; Finger and Lehmann 2012). Finally, some studies have found a "loyalty effect" in which a farmer enrolled in an insurance program continues to participate in the next period regardless of premiums or past claims (Enjolras and Sentis 2011; Uzea et al. 2014a, 2014b). 
In expected utility theory, risk-averse agents should fully insure against unfavorable events if the provided insurance is actuarially fair (Hwang 2015; Du, Feng, and Hennessy 2016). Thus, participation in AgriStability levels should be high and consistent under expected utility theory. An alternative descriptive model of choice under uncertainty that may explain the low demand for insurance is prospect theory (Barberis 2013; Babcock 2015). Eckles and Wise (2011) use prospect theory to explain why there is a lack of demand to insure high-loss, small probability events and a high demand to insure small losses. Eckles and Wise (2011) hypothesize that individuals take action to avoid losses and maximize gains and choose insurance coverage to minimize the experience of a loss should one occur. In the context of insurance decisions, loss aversion means individuals weigh losses more heavily than gains, and they are willing to take on additional risk to avoid feeling a loss. Loss aversion decreases the demand for insurance because individuals may regard insurance as a risky investment that can cause losses, rather than solely as a protection measure (Babcock 2015; Hwang 2015).

The aim of this study is to investigate factors affecting withdrawal from AgriStability using a farm-level time-series framework that incorporates the theoretical concepts of loss aversion and reference dependence. The study provides insight into how farmers perceive and utilize government-funded risk management programs (e.g., BRM programs). Empirical findings in the study showed that both revenue increase or decrease relative to the previous program year would decrease the possibility of withdrawal from the BRM programs, suggesting that BRM programs were used by producers as both a risk management tool and as an investment strategy for speculative earnings, though the preference for the former was stronger than the latter. Moreover, smaller program payments or no payments in two consecutive years significantly increased the likelihood of withdrawal, implying the existence of speculative tendency of enrollment and impatience for the payoffs. These results increased the understanding of the drivers of withdrawal behavior associated with AgriStability and provided insights on how the risk management programs can be modified to increase enrollment and provide the desired support to producers.

\section{Conceptual Framework}

\section{Expected Utility}

Participation in an insurance program has been typically modelled by assuming a producer maximizes his/her expected utility of profits $\left(\pi_{t}\right)$ which is a random variable dependent on the unknown states of nature $(\theta)$ as represented by the probability density function $g(\theta)$. The expected utility of withdrawal or nonparticipation $\left(\mathrm{EU}_{W}\right)$ is expressed as:

$$
\mathrm{EU}_{W}\left(\pi_{t}\right)=\int_{\theta_{\min }}^{\theta_{\max }} U\left[\pi_{t}(\theta)\right] g(\theta) d \theta
$$


whereas the expected utility of participation $\left(\mathrm{EU}_{P}\right)$ is given by

$$
\mathrm{EU}_{P}\left(\pi_{t}\right)=\int_{\theta_{\min }}^{\theta} U\left[\pi_{t}(\theta)+P(\theta)-F\right] g(\theta) d \theta+\int_{\theta}^{\theta_{\max }} v\left[\pi_{t}(\theta)-F\right] g(\theta) d \theta
$$

where $P(\theta)$ is the indemnity or program payment received, $F$ is the premium or program fee paid, and $\theta^{*}$ is the state of nature implicitly defined by the change in program year margin required to trigger a payment The payment function $P$ $(\theta)$ for an individual producer based on the structure of the AgriStability program is, for example:

$$
P(\theta)=\delta \times 0.7 \times\left[0.7 \mathrm{RM}_{t}-\operatorname{PYM}(\theta)_{t}\right]
$$

where $\delta=\left\{\begin{array}{l}1 \text { if } \mathrm{PYM}_{t}<0.7 \mathrm{RM}_{t} \\ 0 \text { if } \mathrm{PYM}_{t} \geq 0.7 \mathrm{RM}_{t}\end{array}\right.$ and $\mathrm{PYM}_{t}$ is the program margin in year $t$, and $\delta$ indicates if a program payment is made. The program margin is defined as all allowable revenues minus all allowable expenses, and a farm will observe this margin when the farm income tax is filed in the following year. A payment will be received $(\delta=1)$ if the program year margin fell below 70 percent of the five-year reference margin $\mathrm{RM}_{t}$ (five-year moving average of the program margin), and the payment is equal to 70 percent of this gap. By evaluating the expected utility of withdrawing from AgriStability compared to the expected utility of remaining enrolled, the decision to remain enrolled results if $\mathrm{EU}_{\mathrm{Pi}}-\mathrm{EU}_{\mathrm{Wi}}>0$ and the producer will withdraw if $\mathrm{EU}_{\mathrm{Pi}}-\mathrm{EU}_{\mathrm{Wi}}<0$.

\section{Prospect Theory}

Rather than absolute levels of an outcome as is assumed in expected utility theory (EU), an alternative is to assume that an individual's preferences are determined by changes in outcomes relative to a reference point, since individuals tend to be more sensitive to losses in wealth than to gains (Rabin 1998). Prospect theory (PT) was developed by Kahneman and Tversky (1979) as an alternative to the restrictive assumption embedded within expected utility theory. The core principle of prospect theory is reference dependence in which individuals evaluate a decision based on losses or gains from a reference point or initial endowment, rather than the prospect's effect on final wealth (Eckles and Wise 2011). In addition, the assumptions of loss aversion, implying losses have a larger effect on welfare than corresponding gains, and diminishing sensitivity, where an individual reacts more strongly to smaller gains and losses than to larger ones, are consistent with empirical findings (Freund and Ozden 2008).

DellaVigna (2007) propose that individuals who exhibit prospect theory preferences evaluate the lottery $(x, p ; y, 1-p)$ as $w(p) v(x-r)+w(1-p)$ $v(y-r)$, where $v$ is value function which is defined over differences from the 
reference point $r$, and $w(p)$ is a probability weighting function which overweights small probabilities and underweights large probabilities. The two key principles of prospect theory relevant to this analysis are (i) that individuals evaluate changes to income relative to a reference point rather than final wealth, and (ii) that individuals value losses more heavily than gains. Given this simplification and the parameters outlined above, individuals will maximize:

$$
\sum_{i=1}^{n} p_{i} v\left(x_{i} \mid r\right)
$$

where the value function is defined as

$$
v\left(x_{i} \mid r\right)= \begin{cases}x-r & \text { if } x \geq r \\ \lambda(x-r) & \text { if } x<r\end{cases}
$$

and $\lambda$ is a measure of loss aversion that is greater than 1 . Tversky and Kahneman (1992) estimate this loss aversion measure to be approximately 2.25 , or that losses are weighted roughly twice as heavily as gains.

The principles of reference dependence and loss aversion are incorporated into a model of choice under uncertainty to determine how prospect theory preferences affect the decision to withdraw from AgriStability. Expected utility now includes the previous years' income $\pi_{t-1}$ as the reference point, i.e. $f\left(\pi_{t}, \pi_{t-1}\right)$. The value function that a producer maximizes for the case of withdrawal from AgriStability is defined as:

$$
\mathrm{EV}_{W}\left(\pi_{t} \mid \pi_{t-1}\right)=\int_{\theta_{\min }}^{\theta_{\max }} u\left[\pi_{t}(\theta)+f\left(\pi_{t}(\theta)-\pi_{t-1}\right)\right] g(\theta) d \theta
$$

where

$$
f\left(\pi_{t}(\theta)-\pi_{t-1}\right)=\left\{\begin{array}{cc}
a\left(\pi_{t}-\pi_{t-1}\right) & \text { if } \pi_{t} \geq \pi_{t-1} \\
b\left(\pi_{t}-\pi_{t-1}\right) & \text { if } \pi_{t}<\pi_{t-1}
\end{array}\right.
$$

and $b$ is a parameter capturing loss aversion with $b>a>0$. The measure of loss aversion scales utility so losses are valued more than gains. The expected utility equation for the case of continued enrollment is expressed as:

$$
\begin{aligned}
E V_{P}\left(\pi_{t} \mid \pi_{t-1}\right)= & \int_{\theta_{\min }}^{\theta} v\left[\pi_{t}(\theta)+f\left(\pi_{t}(\theta)-\pi_{t-1}\right)+P(\theta)-F\right] g(\theta) d \theta \\
& +\int_{\theta}^{\theta_{\max }} v\left[\pi_{t}(\theta)+f\left(\pi_{t}(\theta)-\pi_{t-1}\right)-b F\right] g(\theta) d \theta
\end{aligned}
$$

where $f\left(\pi_{t}(\theta)-\pi_{t-1}\right)$ is given by (7), and like (3), $P(\theta)$ is the payment function, $F$ is the program fee, $g(\theta)$ is the probability density, and $\theta^{*}$ is the state of nature. 
The producer will remain enrolled in AgriStability as long as $\mathrm{EV}_{\mathrm{P}}-\mathrm{EV}_{\mathrm{W}}>0$. Variables that decrease $\mathrm{EV}_{P}$ or increaseEV $\mathrm{W}_{W}$, have the effect of increasing the likelihood of withdrawal from AgriStability, and the opposite is true for variables that increase $\mathrm{EV}_{P}$ or decrease $\mathrm{EV}_{W}$.

\section{Program Margin and the Changes Over Time}

To be more detailed, increasing historical net income increases the program margin and subsequently the reference margin (five-year Olympic average excluding the highest and lowest program margins) on which AgriStability payments are based. The higher expected value of a program payment increases the value of remaining in AgriStability and decreases the likelihood of withdrawal. Relative to equations (2) and (8), an increase in $\pi_{t-1}$ will cause $\mathrm{EU}_{W}$ to decrease since the $f\left(\pi_{t}(\theta)-\pi_{t-1}\right)$ term will be smaller. This would indicate the producer is more likely to stay enrolled based on the expression $\mathrm{EU}_{\mathrm{P}}-\mathrm{EU}_{\mathrm{W}}>0$.

Hypothesis 1: Farms with higher program margins show lower possibilities to withdraw from the insurance program (i.e., an income effect based on EU theory).

The key principle of sensitivity to losses compared to gains associated with prospect theory is tested by calculating the change in income from the previous year. If $\left(\pi_{t}(\theta)-\pi_{t-1}\right)$ is positive (negative), then $\mathrm{EV}_{W}$ will increase (decrease); a producer is more likely to exit the program if they experience a gain in net income and to remain enrolled if they experience a loss. The changes in net income have similar effects on $\mathrm{EV}_{P}$ but result in the opposite participation effect (i.e., gain in net income will cause $\mathrm{EV}_{P}$ to increase, which increases the likelihood of participation; loss in net income will cause $\mathrm{EV}_{P}$ to decrease, which increases likelihood of withdrawal). However, a loss in net income also increases the likelihood of a program payment which will cause $\mathrm{EV}_{P}$ to increase and hence results in an increase in the likelihood of continued participation. The expected sign of the gain and loss variables are therefore ambiguous, with the sign on the loss variable depending on whether the loss is large enough to trigger a payment.

If a farm treats AgriStability as an investment strategy to generate additional income (i.e., payments), it is expected to stay enrolled when experiencing an increase in the program margin. A decrease in the program margin makes the downside risk more salient to the farm. A farm that considers the government business income insurance program as a risk management tool is also expected to stay enrolled if it experiences margin decreases in previous years.

Hypothesis 2a: Increases in program margin decrease the possibility of withdrawal from the program (i.e., participation as investment). 
Hypothesis 2b: Decreases in program margin decrease the possibility of withdrawal from the program (i.e., participation as risk management).

Hypothesis 2c: Decreases in program margin have larger effects on withdrawal decisions than increases in margin (based on Prospect Theory).

\section{Insurance Payment and Payment History}

In addition to the program margin and margin historical changes, previous program payments would be a second source for farm entities' gain-loss evaluation. Based on equation (2), the larger the AgriStability program payment $P(\theta)$, the higher the expected utility from enrollment, which means the producer is less likely to withdraw from the program, giving an expected negative sign on the variable.

Hypothesis 3a: Farms with higher program payments show lower possibilities of withdrawal from the insurance program (i.e., a gain evaluation).

Brown and Finkelstein (2008) find that individuals view insurance as an investment and evaluate the expected gains or losses associated with purchasing a policy, or in our case choosing to enroll in AgriStability. Hwang (2015) echoes this theory, explaining how insurance can be viewed as a risky gamble rather than as a wealth protection measure. In the context of AgriStability, producers who are participating will lose the program fee if payment is not triggered (i.e., if the program year margin does not fall below a certain percentage of the historical reference margin), perhaps viewing the insurance program itself as a risk. Further, Hwang (2015) asserts that prospect theory individuals ignore diversification effects, meaning they evaluate the insurance decision in isolation for existing risks, instead focusing on the insurance policy's own value. More recently, Du, Feng, and Hennessy (2016) and Babcock (2015) also investigated farm insurance demand as an investment strategy (for subsidy) versus a risk management tool.

Therefore, no payment in the previous year is expected to increase the likelihood of withdrawal, because the second term of equation (8) $\int_{\theta}^{\theta_{\max }} v\left[\pi_{t}(\theta)+\right.$ $\left.f\left(\pi_{t}(\theta)-\pi_{t-1}\right)-b F\right] g(\theta) d(\theta)$ which is used to calculate $\mathrm{EV}_{P}$ will be smaller than if the producer were not enrolled. This means $\mathrm{EV}_{\mathrm{P}}-\mathrm{EV}_{\mathrm{W}}<0$, and the producer is more likely to withdraw. Moreover, program payment history would also influence participation decisions via the gain-loss "mental" calculation. The exact payment amount, as well as whether or not there is no payment, matters.

Hypothesis 3b: No payment in previous years increases the possibility of withdrawal (i.e., a loss evaluation). 


\section{Data}

\section{Data Sources}

The Ontario Farm Income Database (OFID) is used for the empirical analysis. OFID is an administrative database managed by the Ontario Ministry of Agriculture, Food and Rural Affairs (OMAFRA), which documents the annual farm income tax returns for all agricultural related farm business entities in the province of Ontario, Canada. The database includes detailed yearly farm financial and operational information as well as participation and program payment information for government-sponsored Business Risk Management (BRM) programs including AgriStability. This study focuses on the years between 2003 and 2013, which includes two five-year themes of the BRM program reforms, i.e., Growing Forward (GF 2003-2007) and Growing Forward 2 (GF2 2008-2012). The payment structure of the BRM program and the longitudinal feature of the OFID data jointly allow us to model the gain-loss framework and empirically test against the conventional expected utility framework. For the purpose of this study, the final sample includes a farm in a certain year if this farm participated in the BRM program in the previous year. This sample allows us to model a farm's program withdrawal behaviors conditional on previous participation status.

The beef sector is selected for investigation. Beef producers do not have access to production insurance like crop farmers, meaning AgriStability is the main risk management program available to them from the government. A farm entity is considered a beef farm in OFID if more than 50 percent of its annual operational revenue comes from the sector. It is possible that the same farm is categorized into different sectors across years. In order to obtain a farm entity's dynamic operational information, the study sample includes all existing years of a farm entity in the database so long as the farm entity was considered a beef farm for at least one year over the study period.

\section{Study Sample}

The number and percentage of beef farms in OFID by revenue class between 2003 and 2013 are listed in Table 1 . The total number of beef farms fell by approximately 20 percent from nearly 8,000 in 2003 to 6,285 in 2013 . The decline occurred primarily in the middle three revenue categories, as the number of farms selling less than $\$ 10,000$ stayed relatively constant over the decade and the number of beef farmers selling more than $\$ 500,000$ increased from 433 in 2003 to 557 in 2013.

The trends in withdrawal from AgriStability for Ontario beef farmers between 2003 and 2013 is given in Table 2. AgriStability is the primary mechanism that individual beef farmers can utilize to protect themselves against large income losses that may arise from low commodity prices, rising input prices, or production losses. The absolute number of farms withdrawing from 
AgriStability in a given year does not change drastically over the ten-year period. However, the percentage of farms withdrawing is increasing over time across all revenue sales classes. The top-three classes all have a withdrawal rate increase of around 9 percent over the period; for example, the over$\$ 500,000$ category starts off with 1.9 percent of farms withdrawing in 2003 (i.e., five farms withdrawing from 262 participating ones) to 11.7 percent of farms withdrawing in 2013. The two lowest income categories experience larger rates of withdrawal, with the largest in the 0 to $\$ 10,000$ category from 10.3 percent in 2003 to 28.6 percent in 2013. A detailed list of program participation rates specific to year and farm revenue category can be found in the Appendix Table A1.

Summary statistics for all observations of a farm participating in AgriStability in the previous year of observation are given in Table 3. A total of 28,390 farmyear observations, representing 6,138 farm operations, are in the sample over the period between 2003 and 2013. Comparing this conditional sample of farms that participated in AgriStability in the previous year to the overall unconditional distribution of beef farms by revenue category (Table 1), it indicates higher percentages in Table 3 (the conditional sample) for the larger farms, i.e., participation rates in AgriStability are higher for farms with more sales. Conditional on program enrollment in the previous year, the average withdrawal rate was about 13 percent, with larger revenue categories having lower rates than the smaller sales farms.

\section{Empirical Model}

\section{Model Specification and Hypothesis Testing}

The conditional probability of withdrawal from AgriStability is estimated with the following regression:

$$
\begin{aligned}
\operatorname{Prob}\left(\text { Withdrawal }_{t}\right)= & \beta_{1}{\text { Program } \text { Margin }_{t-1}+\beta_{2} \text { Margin Increase }_{t-1}} \\
& +\beta_{3} \text { Margin Decrease }_{t-1}+\beta_{4} \text { Payment }_{t-2} \\
& \left.+\beta_{5} I \text { (No Payment }\right)_{t-2}+\theta \text { Control }+\epsilon
\end{aligned}
$$

or alternatively,

$$
\begin{aligned}
\operatorname{Prob}\left(\text { Withdrawal }_{t}\right) & =\delta_{1}{\text { Program } \text { Margin }_{t-1}+\delta_{2} \text { Margin Difference }_{t-1}} \\
& +\delta_{3} I(\text { Margin Increase })_{t-1}+\delta_{4} \text { Payment }_{t-2} \\
& +\delta_{5} I(\text { No Payment })_{t-2}+\theta \text { Control }+\epsilon
\end{aligned}
$$

The decision to withdraw from the AgriStability program in a certain year given that the farm was previously enrolled (Withdrawal ${ }_{t}=1$ | Participation $_{t-1}=1$ ) depends on the value of the potential payment to be 
Table 1. Number (Percentage) of Ontario Beef Farms, 2003-2013

\begin{tabular}{|c|c|c|c|c|c|c|}
\hline \multirow[b]{2}{*}{ Year } & \multirow[b]{2}{*}{$>0 \&<10$} & \multicolumn{5}{|c|}{ Revenue Class (\$ thousands) } \\
\hline & & $\geqslant 10 \&<100$ & $\geqslant 100 \&<250$ & $\geqslant 250 \&<500$ & $\geqslant 500$ & Total \\
\hline 2003 & $1,181(14.8 \%)$ & $4,527(56.8 \%)$ & $1,245(15.6 \%)$ & $589(7.4 \%)$ & $433(5.4 \%)$ & 7,975 \\
\hline 2004 & $1,509(18.7 \%)$ & $4,560(56.5 \%)$ & $1,094(13.6 \%)$ & $553(6.9 \%)$ & $349(4.3 \%)$ & 8,065 \\
\hline 2005 & $1,330(16.0 \%)$ & $4,906(58.9 \%)$ & $1,109(13.3 \%)$ & $563(6.8 \%)$ & $419(5.0 \%)$ & 8,327 \\
\hline 2006 & $1,370(16.9 \%)$ & $4,647(57.4 \%)$ & $1,101(13.6 \%)$ & $559(6.9 \%)$ & $422(5.2 \%)$ & 8,099 \\
\hline 2007 & $1,581(19.2 \%)$ & $4,517(54.9 \%)$ & $1,109(13.5 \%)$ & $566(6.9 \%)$ & $458(5.6 \%)$ & 8,231 \\
\hline 2008 & $1,426(17.9 \%)$ & $4,322(54.3 \%)$ & $1,162(14.6 \%)$ & $546(6.9 \%)$ & $508(6.4 \%)$ & 7,964 \\
\hline 2009 & $1,524(20.0 \%)$ & $4,107(53.2 \%)$ & $1,088(14.1 \%)$ & $518(6.7 \%)$ & $469(6.1 \%)$ & 7,706 \\
\hline 2010 & $1,248(17.4 \%)$ & $3,770(52.6 \%)$ & $1,156(16.1 \%)$ & $506(7.1 \%)$ & $487(6.8 \%)$ & 7,167 \\
\hline 2011 & $1,146(16.3 \%)$ & $3,610(51.4 \%)$ & $1,190(16.9 \%)$ & $544(7.7 \%)$ & $537(7.6 \%)$ & 7,027 \\
\hline 2012 & $1,059(16.1 \%)$ & $3,229(49.0 \%)$ & 1,183 (18.0\%) & $556(8.4 \%)$ & $557(8.5 \%)$ & 6,584 \\
\hline 2013 & $1,007(16.0 \%)$ & $3,091(49.2 \%)$ & $1,116(17.8 \%)$ & $514(8.2 \%)$ & 557 (8.9\%) & 6,285 \\
\hline
\end{tabular}

Source: Ontario Farm Income Data base internal calculations, OMAFRA. 
Table 2. Number (Percentage) of Producers Withdrawing from AgriStability by Year and Revenue Size, 2003-2013

\begin{tabular}{|c|c|c|c|c|c|}
\hline \multirow[b]{2}{*}{ Year } & \multicolumn{5}{|c|}{ Revenue Class ( $\$$ thousands) } \\
\hline & $>0 \&<10$ & $\geqslant 10 \&<100$ & $\geqslant 100 \&<250$ & $\geqslant 250 \&<500$ & $\geqslant 500$ \\
\hline 2004 & $68(10.3 \%)$ & $192(6.4 \%)$ & $15(2.2 \%)$ & $6(1.6 \%)$ & $5(1.9 \%)$ \\
\hline 2005 & $33(8.5 \%)$ & $138(4.6 \%)$ & $22(3.1 \%)$ & $6(1.6 \%)$ & $3(0.9 \%)$ \\
\hline 2006 & $59(14.9 \%)$ & $301(10.8 \%)$ & $40(5.5 \%)$ & $13(3.2 \%)$ & $8(2.5 \%)$ \\
\hline 2007 & $70(18.7 \%)$ & $234(10.1 \%)$ & $25(4.0 \%)$ & $18(5.0 \%)$ & $12(3.7 \%)$ \\
\hline 2008 & $41(13.7 \%)$ & $225(11.0 \%)$ & $41(6.6 \%)$ & $17(5.1 \%)$ & $17(4.8 \%)$ \\
\hline 2009 & $50(17.7 \%)$ & $229(12.6 \%)$ & $35(6.8 \%)$ & $12(3.9 \%)$ & $18(5.9 \%)$ \\
\hline 2010 & $30(16.5 \%)$ & $166(10.4 \%)$ & $34(6.4 \%)$ & $10(3.4 \%)$ & $13(4.2 \%)$ \\
\hline 2011 & $30(30.0 \%)$ & $205(15.3 \%)$ & $50(9.6 \%)$ & $17(5.7 \%)$ & $16(5.1 \%)$ \\
\hline 2012 & $16(20.5 \%)$ & $155(15.2 \%)$ & $51(11.7 \%)$ & $23(9.0 \%)$ & $14(4.4 \%)$ \\
\hline 2013 & $20(28.6 \%)$ & $154(16.9 \%)$ & $43(11.6 \%)$ & $25(11.1 \%)$ & 39 (11.7\%) \\
\hline
\end{tabular}

Note: Withdrawal defined as participating in AgriStability in time period $t-1$ and not participating in AgriStability in time $t$.

Source: Ontario Farm Income Data Base author's calculations, OMAFRA.

received within both the expected utility (2) and prospect theory (8) approach. The value of participation (or withdrawal) hence depends on the farm's program margin in the previous year (Program $\operatorname{Margin}_{t-1}$ ), which is calculated as allowable incomes minus allowable expenses. Hypothesis 1 predicts positive value of $\beta_{1}$ and $\theta_{1}$.

The gain-loss framework from Prospect Theory is tested by the variables measuring the program margin changes. Program margin changes experienced in the last year $t-1$ are derived by subtracting the program $\operatorname{margin}_{t-2}$ from the program margin ${ }_{t-1}$. Note that in reality at the beginning of each calendar year $t$, a farm business owner will make a decision on whether or not to participate in the AgriStability program for the current (calendar/program) year when s/he is handling the previous year's farm income tax return. At that time, s/he only knows the revenue (or program) margin and changes in the previous year $t-1$ and the exact values of program payment for the years before last year, i.e., $t-2, t-3$ and so on.

In equation (9), Margin Increase $t_{t-1}$ for a certain farm is defined as the value of margin change if it is positive, and 0 otherwise. Similarly, Margin Decrease ${ }_{t-1}$ is defined as the value of margin change if it is negative, and 0 otherwise. Hypothesis $2 \mathrm{a}$ and $2 \mathrm{~b}$ predict that $\beta_{2}$ and $\beta_{3}$ are negative. Hypothesis $2 \mathrm{c}$ predicts that $\beta_{2}<\beta_{3}$.

Equation (10) is different from (9), such that Margin Difference ${ }_{t-1}$ is defined as the absolute value of margin change, and the dummy indicator I(Margin Increase $)_{t-1}$ equals to 1 if margin changes are positive. Margin Difference 
measures the magnitude of margin fluctuation regardless of increase or decrease, and the margin increase dummy indicator differentiates the farms with positive margin changes from those with negative ones. According to Hypothesis $2 \mathrm{a}, \mathrm{b}$, and c, $\delta_{2}$ is negative (i.e., risk management needs) and $\delta_{3}$ is positive (i.e., an investment attempt that will offset the risk management needs).

Payment $_{t-2}$ is the value of payment in the previous year. $I$ (No Payment $)_{t-2}$ indicates if a farm did not get any payment in year $t-2$. Hypothesis $3 \mathrm{a}$ predicts negative $\beta_{4}$ and $\delta_{4}$. Hypothesis $3 \mathrm{~b}$ predicts positive $\beta_{5}$ and $\delta_{5}$. In order to capture the historical effects of no payment, an additional indicator of no payment in year $t-3$ is also included in the model with the expectation that history of no payment yields different effects across years.

The model also controls farm characteristics such as farm sector concentration, business diversification, farm type, and other government payments, etc. A structural change dummy variable is also included to capture the policy effects after 2008, when Growing Forward 2 was implemented.

\section{Variable Description}

According to Table 3, the average program margin from the previous year was approximately $\$ 7,970$ for the sample. Program margin was negative for the lowest two revenue categories, and the remaining three higher categories ranged from $\$ 8,740$ to $\$ 60,780$. The average program payment in the sample was about $\$ 6,520$. The payment size ranged widely from as low as $\$ 2,130$ for the smallest farm category to as high as $\$ 27,030$ for the biggest farm category, even though the probability of having a non-zero payment was higher in the smaller farm categories than the bigger ones.

In addition to program margin changes and payment history, a series of farm operation variables are included as control variables. Sector concentration is calculated as the percentage share of current year operation revenue coming from the beef sector. Sector concentration ranged from 0.84 to 0.93 across revenue categories. The Diversification index measures the balance and diversification of farm operation among alternative revenue streams, where 0 means no diversification and 1 means perfectly diversified. The Diversification index ranged from 0.34 to 0.57 . Larger farms (proportionally more of which are feedlot farms) are less diversified. Farm type includes three categories: cow-calf and feedlot operations within the beef sector, and other type, when a beef farm switches sectors in some certain years; 13.3 percent of the sample were feedlot farms, 3.6 percent were others (i.e., when a farm was categorized as other than beef sector in certain program years), and the remaining 80 percent were cow-calf farms. The farm type distribution varied significantly across revenue categories, with the majority of cow-calf operations being in the three lowest revenue categories, and the majority of feedlot operations in the two highest revenue categories. 
Table 3. Summary Statistics

\begin{tabular}{|c|c|c|c|c|c|c|}
\hline \multirow[b]{2}{*}{ Variable } & \multirow[b]{2}{*}{ Full Sample } & \multicolumn{5}{|c|}{ Revenue Class (\$ thousands) } \\
\hline & & $0-\$ 10$ & $\$ 10-\$ 100$ & $\$ 100-\$ 250$ & $\$ 250-\$ 500$ & $>\$ 500$ \\
\hline \multicolumn{7}{|l|}{ Dependent Variable } \\
\hline \multirow[t]{2}{*}{ \% Withdrawal } & 0.13 & 0.15 & 0.10 & 0.06 & 0.05 & 0.04 \\
\hline & $(0.34)$ & $(0.35)$ & $(0.30)$ & $(0.24)$ & $(0.21)$ & $(0.21)$ \\
\hline \multicolumn{7}{|l|}{ Explanatory Variables } \\
\hline \multirow[t]{2}{*}{ Program margin ${ }_{t-1}\left({ }^{\prime} 000\right)$} & 7.97 & -3.07 & -1.20 & 8.74 & 14.10 & 60.78 \\
\hline & $(179.45)$ & $(18.76)$ & (31.81) & $(58.04)$ & $(81.28)$ & (551.92) \\
\hline \multirow{2}{*}{ Prog. margin increase $e_{t-1}\left({ }^{\prime} 000\right)$} & 63.45 & 162.47 & 45.26 & 23.44 & 123.97 & 104.59 \\
\hline & $(4266.08)$ & (7124.19) & $(4658.07)$ & $(230.31)$ & $(4920.70)$ & $(464.08)$ \\
\hline \multirow[t]{2}{*}{ Prog. margin decrease $e_{t-1}\left({ }^{\prime} 000\right)$} & 20.43 & 4.30 & 7.81 & 18.20 & 28.47 & 99.75 \\
\hline & $(162.07)$ & $(12.40)$ & $(27.58)$ & $(47.50)$ & $(61.56)$ & $(496.66)$ \\
\hline \multirow[t]{2}{*}{$\%$ Program margin increase $e_{t-1}$} & 0.51 & 0.49 & 0.50 & 0.51 & 0.52 & 0.51 \\
\hline & $(0.50)$ & $(0.50)$ & $(0.50)$ & $(0.50)$ & $(0.50)$ & $(0.50)$ \\
\hline \multirow[t]{2}{*}{ AgriStability payments $_{t-2}\left({ }^{\prime} 000\right)$} & 6.52 & 2.13 & 3.23 & 6.08 & 8.65 & 27.03 \\
\hline & (35.32) & $(4.37)$ & $(8.26)$ & (19.63) & $(23.95)$ & $(102.51)$ \\
\hline \multirow[t]{2}{*}{$\%$ No payment in $t-2$} & 0.57 & 0.50 & 0.54 & 0.62 & 0.63 & 0.68 \\
\hline & $(0.49)$ & $(0.50)$ & $(0.50)$ & $(0.49)$ & $(0.48)$ & $(0.47)$ \\
\hline \multirow[t]{2}{*}{$\%$ No payment in $t-3$} & 0.28 & 0.23 & 0.25 & 0.31 & 0.32 & 0.38 \\
\hline & $(0.45)$ & $(0.42)$ & $(0.43)$ & $(0.46)$ & $(0.47)$ & $(0.49)$ \\
\hline \multirow[t]{2}{*}{ Sector concentration $_{t-1}$} & 0.872 & 0.925 & 0.880 & 0.848 & 0.837 & 0.864 \\
\hline & $(0.16)$ & $(0.14)$ & $(0.16)$ & $(0.16)$ & $(0.16)$ & $(0.15)$ \\
\hline
\end{tabular}




\begin{tabular}{|c|c|c|c|c|c|c|}
\hline Diversification index $_{t-1}$ & $\begin{array}{r}0.518 \\
(0.23)\end{array}$ & $\begin{array}{r}0.541 \\
(0.18)\end{array}$ & $\begin{array}{r}0.573 \\
(0.19)\end{array}$ & $\begin{array}{c}0.479 \\
(0.26)\end{array}$ & $\begin{array}{r}0.410 \\
(0.26)\end{array}$ & $\begin{array}{r}0.341 \\
(0.25)\end{array}$ \\
\hline \multicolumn{7}{|l|}{ Operation Type } \\
\hline \multirow[t]{2}{*}{ Feedlot } & 0.133 & 0.001 & 0.001 & 0.056 & 0.521 & 0.795 \\
\hline & $(0.34)$ & $(0.03)$ & $(0.03)$ & $(0.23)$ & $(0.50)$ & $(0.40)$ \\
\hline \multirow[t]{2}{*}{ Other } & 0.036 & 0.076 & 0.022 & 0.026 & 0.047 & 0.095 \\
\hline & $(0.19)$ & $(0.27)$ & $(0.15)$ & $(0.16)$ & $(0.21)$ & $(0.29)$ \\
\hline \multirow[t]{2}{*}{ Adhoc payment from beef ${ }_{t-1}\left({ }^{\prime} 000\right)$} & 2.460 & 0.190 & 0.590 & 1.830 & 3.210 & 14.610 \\
\hline & $(26.49)$ & $(0.73)$ & $(5.45)$ & $(8.13)$ & (12.37) & $(79.66)$ \\
\hline \multirow[t]{2}{*}{ Adhoc payment from other ${ }_{t-1}\left({ }^{\prime} 000\right)$} & 5.020 & 0.550 & 1.490 & 3.990 & 6.910 & 27.280 \\
\hline & $(25.39)$ & $(1.29)$ & $(2.77)$ & $(7.91)$ & $(9.91)$ & $(74.49)$ \\
\hline
\end{tabular}


Two measures of government ad hoc payments, i.e., targeting to the beef sector and targeting to farm entities in general, are also included. Year fixed effects and an indicator for years 2008 and later (i.e., after program reform) are also controlled. As with AgriStability, larger farms received substantially larger ad hoc payments from other government programs targeting the beef sector. These payments tended to be associated with disease outbreaks that negatively affected market revenue to the whole beef sector.

\section{Results}

Test of EU vs. PT

The results from the panel logistic regressions of withdrawal behavior $(=1)$ from AgriStability based on equations (9) and (10) are listed in Table 4. Each column represents one regression with a particular combination of program margin and payment history variables. Year fixed effects are included in all regressions. Robust standard errors are clustered by farm entity.

Column 1 of Table 4 (EU) serves as a benchmark and is based on the traditional expected utility theory approach. It shows that the previous year's program margin decreases a farm entity's likelihood of withdrawing from the AgriStability program, given the fact that the farm entity participated in the program in the previous year. The higher the program margin in the previous year, the more likely the farm entity will choose to stay enrolled. The estimated relationship carries the implications of both an income effect (i.e., higher revenue, more ability to pay for the program premiums) and an investment effect (i.e., higher revenue, higher calculated reference margin, and hence higher coverage with higher probability to get payments). A higher program payment in year $t-2$ also encourages stable enrollment. Interestingly, those farm entities who did not get any payment in year $t-2$ are, on average, less likely to withdraw (i.e., more likely to stay enrolled) compared to those who received non-zero payments. The relative magnitudes of these two payment variables imply that those who received smaller payments (e.g., less than $\$ 6,433=1.737 / 0.27$ ) are at disproportionally higher risks of withdrawal than their counterparts (e.g., no payments, or larger payments.)

Prospect theory is incorporated through regressions in columns 2 to 4 of Table 4 with the introduction of gain-loss variables calculated through the changes in the absolute amount of the program margin. Results in Column 2 (PT[1]), following from equation (9), show that farms with higher margin increases and decreases are both more likely to stay enrolled compared to those whose margin changes are smaller. While a declining reference margin increases the likelihood of withdrawal as in the expected utility model (income/investment hypothesis), the negative effects of a margin decrease on withdrawal also highlight the farmers' need for risk management; the greater 
Table 4. Estimated Regression Coefficients Explaining Withdrawal from AgriStability using Expected Utility (EU) and Prospect Theory (PT) Frameworks

\begin{tabular}{|c|c|c|c|c|}
\hline Model & $\mathbf{E U}$ & PT (1) & PT (2) & PT (3) \\
\hline \multirow[t]{2}{*}{ Constant } & -1.804 & -0.990 & -0.981 & -1.948 \\
\hline & $(0.25)^{* * *}$ & $(0.27)^{* * *}$ & $(0.28)^{* * *}$ & $(0.25)^{* * *}$ \\
\hline \multirow{2}{*}{$\begin{array}{l}\text { Ln program } \\
\operatorname{margin}_{t-1}\end{array}$} & -0.019 & -0.0227 & -0.0232 & -0.0219 \\
\hline & $(0.01)^{* * *}$ & $(0.01)^{* * *}$ & $(0.01)^{* * *}$ & $(0.01)^{* * *}$ \\
\hline \multirow{2}{*}{$\begin{array}{l}\text { Ln program margin } \\
\text { increase }_{t-1}\end{array}$} & & -0.0943 & -0.0943 & \\
\hline & & $(0.02)^{* * *}$ & $(0.02)^{* * *}$ & \\
\hline \multirow{2}{*}{$\begin{array}{l}\text { Ln program margin } \\
\text { decrease }_{t-1}\end{array}$} & & -0.115 & -0.115 & \\
\hline & & $(0.02)^{* * *}$ & $(0.02)^{* * *}$ & \\
\hline \multirow{2}{*}{$\begin{array}{l}\text { Ln program margin } \\
\text { difference }_{t-1}\end{array}$} & & & & -0.0761 \\
\hline & & & & $(0.02)^{* * *}$ \\
\hline \multirow{2}{*}{$\begin{array}{l}\text { If program margin } \\
\text { increased }_{t-1}\end{array}$} & & & & 0.895 \\
\hline & & & & $(0.21)^{* * *}$ \\
\hline \multirow{2}{*}{$\begin{array}{l}\text { Ln AgriStability } \\
\text { payments }_{t-2}\end{array}$} & -0.270 & -0.247 & -0.247 & -0.2610 \\
\hline & $(0.03)^{* * *}$ & $(0.03)^{* * *}$ & $(0.03)^{* * *}$ & $(0.03)^{* * *}$ \\
\hline \multirow[t]{2}{*}{ If no payment in $t-2$} & -1.737 & -1.517 & -1.567 & -1.6460 \\
\hline & $(0.23)^{* * *}$ & $(0.24)^{* * *}$ & $(0.24)^{* * *}$ & $(0.23)^{* * *}$ \\
\hline \multirow[t]{2}{*}{ If no payment in $t-3$} & & & 0.1120 & \\
\hline & & & $(0.06)^{*}$ & \\
\hline $\begin{array}{l}\text { McKelvey \& } \\
\quad \text { Zavoina's R }\end{array}$ & 0.1000 & 0.1088 & 0.1084 & 0.1030 \\
\hline Year FE & Yes & Yes & Yes & Yes \\
\hline Observations & 28,390 & 28,390 & 28,390 & 28,390 \\
\hline
\end{tabular}

Robust standard errors in parentheses.

*** is significant at the one percent level $(\mathrm{p}<0.01)$, $^{* *}$ is significant at the 5 percent level $(\mathrm{p}<0.05),{ }^{*}$ is significant at the 10 percent level $(\mathrm{p}<0.1)$.

All monetary variables, such as program margin, margin increase, decrease or (absolute) difference were taken natural logarithm to normalize the data distribution and captured the percentage changes of the corresponding variable with a pre-fix notation "Ln".

PT(1) and (2) are results based on equation 9, and PT (3) is based on equation 10. 
the income loss (i.e., margin decrease) a farm experienced in the previous year, the greater the (perceived) need for farm income protection in the future, and hence a decrease in the likelihood of withdrawal from the program. An F-test of the null hypothesis that margin increase and decrease have equal effects is performed. Results $(F=14.85 ; \mathrm{p}=0.0001)$ reject the null and suggest the needs for risk management has greater impacts on program participation decision than income/investment effects.

Column 3 of Table 4 ([PT(2]) includes an additional dummy indicator of whether a farm received no payment two years before, i.e., payment for program year $t-3$, so as to capture the effects of payment history beyond the immediate previous year, i.e., $t-2$. No payment two years before increases the likelihood of withdrawal, although the magnitude is much smaller than the positive effects of no payment one year before, i.e., $t-2$.

Column 4 ([PT(3]) follows from equation (10) by combining margin increase and decrease into one variable indicating the absolute amount of margin difference (from the previous year, both upward and downward) and using it as a proxy for farm income fluctuations in general. A dummy variable of those farms that experienced income increases is included in the model to differentiate from those who experienced losses. Results show that farm income fluctuations significantly decrease the tendency to withdraw. However, those who experienced gains (income increases) in the previous year are much more likely to withdraw than those who experienced losses. These results are consistent with the other two prospect theory regressions.

\section{Robustness Check}

Using the full prospect theory model PT(2) from Table 4, robustness checks from the inclusions of various combinations of farm characteristics variables are listed in Table 5. Results show that the gain-loss framework is very stable in explaining farmers' withdrawal tendency. Moreover, farm characteristics also explain the decision to exit AgriStability. High sector concentration induces withdrawal, or put it differently, farms with more diverse operations are more likely to stay enrolled. This pattern is further verified via the Diversification index, though this business diversification measure is much less significant than sector concentration. Comparing various types of beef farms, feedlot and others are more likely to stay enrolled than cow-calf farmers. One possible explanation is that cow-calf farms are of smaller scale in operation size, and smaller enterprises are less likely to continue participating in the support program.

Government ad hoc payments, both payments in general and for the beef sector in particular, encourage stable enrollment. Different from the general impression that government ad hoc payment may crowd out BRM program participation, results here show complementary effects. Receiving ad hoc payments at catastrophic events may help to build the trust of government, and in turn motivate farms to stay enrolled in government-sponsored 
Table 5. Regression Results of Prospect Theory Model with other Explanatory Variables

\begin{tabular}{|c|c|c|c|c|c|c|c|}
\hline \multirow[b]{2}{*}{ Models } & \multirow[b]{2}{*}{ PT (l) } & \multicolumn{6}{|c|}{ DV $=$ Prob $($ Withdrawal $=1)$} \\
\hline & & (1) & (2) & (3) & (4) & (5) & (6) \\
\hline \multicolumn{8}{|l|}{ Explanatory Variables } \\
\hline \multirow[t]{2}{*}{ Constant } & -0.981 & -1.670 & -0.725 & -1.580 & -1.317 & -0.158 & -1.02 \\
\hline & $(0.28)^{* * *}$ & $(0.33)^{* * *}$ & $(0.30)^{* *}$ & $(0.38)^{* * *}$ & $(0.28)^{* * *}$ & 0.27 & $(0.33)^{* * *}$ \\
\hline \multirow{2}{*}{ Ln program margin ${ }_{t-1}$} & -0.0232 & -0.0213 & -0.0253 & -0.0229 & -0.0193 & -0.0112 & -0.0072 \\
\hline & $(0.01)^{* * *}$ & $(0.01)^{* * *}$ & $(0.01)^{* * *}$ & $(0.01)^{* * *}$ & $(0.01)^{* * *}$ & $(0.01)^{* * *}$ & $(0.01)^{* * *}$ \\
\hline \multirow{2}{*}{$\begin{array}{l}\text { Ln program margin } \\
\text { increase }_{t-1}\end{array}$} & -0.0943 & -0.0872 & -0.0921 & -0.0884 & -0.0619 & -0.0606 & -0.0274 \\
\hline & $(0.02)^{* * *}$ & $(0.02)^{* * *}$ & $(0.02)^{* * *}$ & $(0.02)^{* * *}$ & $(0.02)^{* * *}$ & $(0.02)^{* * *}$ & $(0.02)$ \\
\hline \multirow{2}{*}{$\begin{array}{l}\text { Ln program margin } \\
\text { decrease }_{t-1}\end{array}$} & -0.1150 & -0.1080 & -0.1160 & -0.1120 & -0.0809 & -0.0801 & -0.044 \\
\hline & $(0.02)^{* * *}$ & $(0.02)^{* * *}$ & $(0.02)^{* * *}$ & $(0.02)^{* * *}$ & $(0.02)^{* * *}$ & $(0.02)^{* * *}$ & $(0.02)^{* *}$ \\
\hline \multirow{2}{*}{$\begin{array}{l}\text { Ln AgriStability } \\
\text { payment }_{t-2}\end{array}$} & -0.2470 & -0.2470 & -0.2600 & -0.2580 & -0.2310 & -0.2230 & -0.211 \\
\hline & $(0.03)^{* * *}$ & $(0.03)^{* * *}$ & $(0.03)^{* * *}$ & $(0.03)^{* * *}$ & $(0.03)^{* * *}$ & $(0.03)^{* * *}$ & $(0.03)^{* * *}$ \\
\hline \multirow[t]{2}{*}{ If no payment in $t-2$} & -1.5670 & -1.5790 & -1.7150 & -1.6940 & -1.4300 & -1.3960 & -1.296 \\
\hline & $(0.24)^{* * *}$ & $(0.24)^{* * *}$ & $(0.25)^{* * *}$ & $(0.25)^{* * *}$ & $(0.24)^{* * *}$ & $(0.24)^{* * *}$ & $(0.24)^{* * *}$ \\
\hline \multirow[t]{2}{*}{ If no payment in $t-3$} & 0.112 & 0.135 & 0.118 & 0.125 & 0.110 & 0.0852 & 0.108 \\
\hline & $(0.06)^{*}$ & $(0.06)^{* *}$ & $(0.07)^{*}$ & $(0.07)^{*}$ & $(0.06)^{*}$ & $(0.06)$ & $(0.06)^{*}$ \\
\hline \multirow{2}{*}{$\begin{array}{l}\text { Sector } \\
\text { concentration }_{t-1}(\%)\end{array}$} & & 0.671 & & 0.782 & & & 0.484 \\
\hline & & $(0.19)^{* * *}$ & & $(0.22)^{* * *}$ & & & $(0.18)^{* * *}$ \\
\hline
\end{tabular}


Table 5. Continued

\begin{tabular}{|c|c|c|c|c|c|c|c|}
\hline \multirow[b]{2}{*}{ Models } & \multirow[b]{2}{*}{ PT (l) } & \multicolumn{6}{|c|}{ DV $=$ Prob $($ Withdrawal $=1)$} \\
\hline & & (1) & $(2)$ & (3) & (4) & (5) & (6) \\
\hline \multirow{2}{*}{ Diversification index $x_{t-1}$} & & & -0.221 & -0.0678 & & & \\
\hline & & & $(0.13)^{*}$ & $(0.14)$ & & & \\
\hline \multicolumn{8}{|l|}{ Operation Type } \\
\hline \multirow[t]{2}{*}{ Feedlot } & & & & & -0.774 & & -0.631 \\
\hline & & & & & $(0.11)^{* * *}$ & & $(0.12)^{* * *}$ \\
\hline \multirow[t]{2}{*}{ Other } & & & & & -0.409 & & -0.47 \\
\hline & & & & & $(0.16)^{* *}$ & & $(0.16)^{* * *}$ \\
\hline \multirow{2}{*}{$\begin{array}{l}\text { Ln beef adhoc } \\
\text { payment }_{t-1}\end{array}$} & & & & & & -0.0802 & -0.0785 \\
\hline & & & & & & $(0.02)^{* * *}$ & $(0.02)^{* * *}$ \\
\hline \multirow{2}{*}{$\begin{array}{l}\text { Ln other adhoc } \\
\text { payment }_{t-1}\end{array}$} & & & & & & -0.124 & -0.117 \\
\hline & & & & & & $(0.01)^{* * *}$ & $(0.01)^{* * *}$ \\
\hline \multirow{2}{*}{$\begin{array}{l}\text { If year 2008-2013 } \\
\text { (GF2) }\end{array}$} & & 1.954 & 1.870 & 1.876 & 1.954 & 1.369 & 1.424 \\
\hline & & $(0.14)^{* * *}$ & $(0.15)^{* * *}$ & $(0.15)^{* * *}$ & $(0.14)^{* * *}$ & $(0.16)^{* * *}$ & $(0.16)^{* * *}$ \\
\hline Year FE & Yes & Yes & Yes & Yes & Yes & No & No \\
\hline $\begin{array}{l}\text { McKelvey \& Zavoina's R- } \\
\text { squared }\end{array}$ & 0.1084 & 0.1106 & 0.1032 & 0.1058 & 0.1237 & 0.1524 & 0.1609 \\
\hline Observations & 28,390 & 28,251 & 25,344 & 25,344 & 27,858 & 28,390 & 25,199 \\
\hline Number of Farms & 6,138 & 6,101 & 5,418 & 5,418 & 6,083 & 6,138 & 5,395 \\
\hline
\end{tabular}

Robust standard errors in parentheses ${ }^{* * *}$ is significant at the one percent level $(\mathrm{p}<0.01),{ }^{* *}$ is significant at the 5 percent level $(\mathrm{p}<0.05),{ }^{*}$ is significant at the 10 percent level $(\mathrm{p}<0.1)$. 
programs. A structural break dummy variable indicating farm-year observations of 2008 and beyond shows significant increase in withdrawal after the BRM programs adjustment in 2008 when premiums were raised while coverages were reduced.

\section{Heterogeneity by Farm Size}

Since farms may behave quite differently depending on size of operation, the full model from Table 5 was estimated separately by revenue category. Results suggest that smaller farms are more responsive to program payments when making participation decisions, while larger farms are more sensitive to their own farm income changes (see Table 6). Different from the pooled regressions, farms in $(\$ 100-250 \mathrm{k})$ and $(>\$ 500 \mathrm{k}+)$ categories show positive effects of margin increase/decrease on withdrawal, suggesting that these farms are less dependent on government programs for risk management or income generation. Table 7 calculated the marginal effects of each explanatory variable on the probability of withdrawal using the functional form of Column 6 in Table 5.

\section{Discussion and Conclusion}

This study developed a gain-loss framework based on prospect theory to understand the dynamic decisions of farm business enterprises on insurance participation over years. The Canadian government-sponsored Business Risk Management (BRM) programs offered an empirical context for this investigation. Using the administrative Ontario Farm Income Database (OFID) 2003 to 2013 and taking the beef sector as the example, this study found that the gain-loss framework predicts and explains the dynamic program participation pattern better than the conventional expected utility framework. Farms were found to be more likely to stay enrolled in the program when they experienced either larger gains or losses in revenue compared to previous years, suggesting that they were using the BRM programs both as an investment strategy (to seek government payments) and as a risk management tool (to protect against business risks), though the effects of revenue losses and hence, risk management needs were stronger than gains. Moreover, farmers were very sensitive to program payment amount and whether or not getting payment itself. Receiving smaller payments (e.g., less than $\$ 6,400$ ) induced higher withdrawal rates compared to bigger payments or even no payments. These findings about payment sensitivity suggest that farmers are subject to Gambler's fallacy, in which, they (falsely) believe that past payments (or alternatively, occurrence of bad market outcomes) predict future ones when the actual possibilities of getting payment should be independent across years (at least from actuarial perspectives).

In addition, findings about farm characteristics in this study also provide helpful insights. For example, highly concentrated and/or smaller scale 
Table 6. Regression Results for Full Model by Revenue Category

\begin{tabular}{|c|c|c|c|c|c|}
\hline \multirow[b]{2}{*}{ Model } & \multicolumn{5}{|c|}{ Revenue Sales Class (\$ thousands) } \\
\hline & $>0 \& \& 10$ & $>10 \&<100$ & $>100 \&<250$ & $>250 \&<500$ & $>\mathbf{5 0 0}$ \\
\hline \multicolumn{6}{|l|}{ Explanatory Variables } \\
\hline \multirow{2}{*}{ Constant } & -0.871 & -1.433 & -4.113 & -0.706 & -6.153 \\
\hline & $(0.97)$ & $(0.45)^{* * *}$ & $(1.03)^{* * *}$ & $(1.78)$ & $(1.87)^{* * *}$ \\
\hline \multirow[t]{2}{*}{ Ln program $\operatorname{margin}_{t-1}$} & -0.016 & 0.003 & 0.013 & -0.025 & 0.026 \\
\hline & $(0.02)$ & $(0.01)$ & $(0.02)$ & $(0.02)$ & $(0.02)$ \\
\hline \multirow[t]{2}{*}{ Ln program margin increase ${ }_{t-1}$} & -0.029 & 0.010 & 0.151 & -0.072 & 0.215 \\
\hline & $(0.06)$ & $(0.02)$ & $(0.07)^{* *}$ & $(0.08)$ & $(0.08)^{* * *}$ \\
\hline \multirow[t]{2}{*}{ Ln program margin decrease $e_{t-1}$} & -0.050 & -0.012 & 0.178 & -0.088 & 0.217 \\
\hline & $(0.06)$ & $(0.02)$ & $(0.07)^{* * *}$ & $(0.08)$ & $(0.08)^{* * *}$ \\
\hline \multirow[t]{2}{*}{ Ln AgriStability payment $t_{t-2}$} & -0.181 & -0.180 & -0.173 & -0.403 & -0.0004 \\
\hline & $(0.08)^{* *}$ & $(0.04)^{* * *}$ & $(0.08)^{* *}$ & $(0.16)^{* * *}$ & $(0.15)$ \\
\hline \multirow[t]{2}{*}{ If no payment in $t-2$} & -0.943 & -0.998 & -1.043 & -3.076 & 0.861 \\
\hline & $(0.65)$ & $(0.33)^{* * *}$ & $(0.74)$ & $(1.41)^{* *}$ & $(1.58)$ \\
\hline \multirow[t]{2}{*}{ If no payment in $t-3$} & 0.152 & 0.206 & -0.0533 & -0.303 & 0.117 \\
\hline & $(0.22)$ & $(0.08)^{* *}$ & $(0.17)$ & $(0.26)$ & $(0.22)$ \\
\hline \multirow[t]{2}{*}{ Sector concentration $_{t-1}(\%)$} & 0.024 & 0.335 & 0.121 & 0.871 & -0.289 \\
\hline & $(0.57)$ & $(0.23)$ & $(0.49)$ & $(0.74)$ & $(0.69)$ \\
\hline \multicolumn{6}{|l|}{ Operation Type } \\
\hline \multirow[t]{2}{*}{ Feedlot } & 19.13 & -1.371 & -0.237 & -0.104 & 0.101 \\
\hline & $(1.15)^{* * *}$ & $(1.31)$ & $(0.34)$ & $(0.24)$ & $(0.34)$ \\
\hline
\end{tabular}




\begin{tabular}{|c|c|c|c|c|c|}
\hline \multirow[t]{2}{*}{ Other } & -0.604 & -0.319 & -0.721 & 0.014 & -0.024 \\
\hline & $(0.41)$ & $(0.22)$ & $(0.51)$ & $(0.56)$ & $(0.46)$ \\
\hline \multirow[t]{2}{*}{ Ln beef adhoc payment $t_{t-1}$} & $-0.140^{*}$ & -0.096 & -0.021 & 0.029 & -0.122 \\
\hline & $(0.08)^{*}$ & $(0.03)^{* * *}$ & $(0.04)$ & $(0.06)$ & $(0.08)$ \\
\hline \multirow{2}{*}{ Ln other adhoc payment $t_{t-1}$} & -0.038 & -0.130 & -0.081 & -0.063 & -0.080 \\
\hline & $(0.03)$ & $(0.01)^{* * *}$ & $(0.03)^{* * *}$ & $(0.04)^{*}$ & $(0.03)^{* * *}$ \\
\hline \multirow[t]{2}{*}{ If year $=2008-2013(\mathrm{GF} 2)$} & 1.477 & 1.313 & 1.637 & 2.564 & 1.523 \\
\hline & $(0.53)^{* * *}$ & $(0.21)^{* * *}$ & $(0.46)^{* * *}$ & $(0.77)^{* * *}$ & $(0.76)^{* *}$ \\
\hline Year FE & No & No & No & No & No \\
\hline Observations & 1,979 & 15,789 & 4,788 & 2,533 & 2,635 \\
\hline Number of Farms & 964 & 4,210 & 1,628 & 884 & 657 \\
\hline
\end{tabular}

Robust standard errors in parentheses $* * *$ is significant at the one percent level $(\mathrm{p}<0.01)$, ** is significant at the 5 percent level $(\mathrm{p}<0.05)$, * is significant at the 10 percent level $(\mathrm{p}<0.1)$. 
Table 7. Marginal Effects of a Change in an Explanatory Variable on the Dependent Withdrawal Variable.

\begin{tabular}{|c|c|c|c|c|}
\hline & \multirow[b]{2}{*}{ Marginal Effect } & \multicolumn{2}{|c|}{ Delta-method } & \multirow[b]{2}{*}{$\mathbf{p}>|\mathbf{z}|$} \\
\hline & & Std. Err. & $\mathbf{z}$ & \\
\hline Ln program margin $\operatorname{mot}_{t-1}$ & -0.01 & 0.01 & -1.20 & 0.23 \\
\hline Ln program margin increase ${ }_{t-1}$ & -0.03 & 0.02 & -1.47 & 0.14 \\
\hline Ln program margin decrease $e_{t-1}$ & -0.04 & 0.02 & -2.49 & 0.01 \\
\hline Ln AgriStability payment $_{t-2}$ & -0.21 & 0.03 & -7.40 & 0.00 \\
\hline If no payment in $t-2$ & -1.30 & 0.24 & -5.37 & 0.00 \\
\hline If no payment in $t-3$ & 0.11 & 0.06 & 1.73 & 0.08 \\
\hline Sector concentration $_{t-1}(\%)$ & 0.48 & 0.18 & 2.72 & 0.01 \\
\hline \multicolumn{5}{|l|}{ Operation Type } \\
\hline Feedlot & -0.63 & 0.11 & -5.96 & 0.00 \\
\hline Other & -0.47 & 0.16 & -2.92 & 0.00 \\
\hline Ln beef adhoc payment $t_{t-1}$ & -0.08 & 0.02 & -4.18 & 0.00 \\
\hline Ln other adhoc payment $t_{t-1}$ & -0.12 & 0.01 & -12.82 & 0.00 \\
\hline If year $=2008-2013(G F 2)$ & 1.42 & 0.16 & 8.71 & 0.00 \\
\hline
\end{tabular}


(cow-calf) farms were found to be more likely to drop out from the program, and in comparison, more diverse and/or bigger scale (feedlot) farms are more likely to stay in the program. This would imply that historical program payments due to one market sector would more likely be used to compensate other sectors. For another example, farmers were found to treat BRM program somewhat complementarily with ad hoc catastrophic payments, whereas these payments are actually designed to cover distinctive (and exclusive) layers of business risks.

While most studies adopting prospect theory and the gain-loss framework are trying to rationalize and predict the behaviors or business decisions observed in the field, it is suggested that such theoretical insights should also be used in a prescriptive way for policy and mechanism design (Barberis 2013). In the current study context, future program designs may focus on the relative changes of program margins over years, payment schedules as well as magnitudes. In the meantime, effective communication and program education would be useful to reduce misunderstandings or misperceptions.

This study is not without limits. First, no information on the timing of losses or timing of program payments was taken into account. Though the administrative data matched the program payments to the exact program year, Antón, Kimura and Martin (2011) show that the mix-match in timing (or long-time wait) between events of income losses and program payments is an important reason for low participation. In extreme cases, this waiting time could be as long as almost two years. Information of these timing indicators would help to explain additional variation of participation beyond the current study.

Second, another challenge of using the gain-loss framework is determining the reference points. The study assumes farmers would make decisions relative to their previous year's program margins. However, other metrics could also serve as the reference points, such as the reference margins (i.e., five-year Olympic moving averages of program margins), paid premiums alone, or paid premiums relative to program payments, and which one a farm actually adopts to making decisions could also vary substantially. This brings the identification concerns of endogenous reference points as suggested by Barberis (2013).

Third, unobservable and potential confounders are always challenges for causal inferences. In this study context, for example, some common approaches to avoid or delay effective income tax from accounting perspectives, such as farm durable assets accumulation, long-term debt, and changing inventory stocks, could change the calculated program margins over years. For another example, off-farm income or sectors switches (i.e., major share of revenue coming from different operation sectors across years) could work as risk-coping strategies that are substitutes to BRM program participation. 


\section{References}

AAFC. 2013. AgriStability Program Handbook. Ottawa, Canada. AAFC No: 19960E.

Antón, J., S. Kimura, and R. Martini. 2011. Risk Management in Agriculture in Canada. OECD Food, Agriculture and Fisheries Working Papers, No. 40, OECD Publishing. Available at http://dx.doi.org/10.1787/5kgj0d6189wg-en.

Babcock, B.A. 2015. "Using Cumulative Prospect Theory to Explain Anomalous Crop Insurance Coverage Choice." American Journal of Agricultural Economics 97(5): 1371-1384.

Barberis, N.C. 2013. "Thirty Years of Prospect Theory in Economics: A Review and Assessment." Journal of Economic Perspectives 27(1): 173-96.

Brown, J.R., and A. Finkelstein. 2008. "The Interaction of Public and Private Insurance: Medicaid and the Long-Term Care Insurance Market." American Economic Review 98(3): 1083-1102.

Cabas, J.H., A.J. Leiva, and A. Weersink. 2008. "Modeling Exit and Entry of Farmers in A Crop Insurance Program." Agricultural and Resource Economics Review 37(1): 92-105.

Chen, K.Z., and K.D. Meilke. 1996. "A Reevaluation of Canada's Safety Net Programs for Agriculture." Canadian Journal of Agricultural Economics/Revue Canadienne d'agroeconomie 44(4): 361-68.

Coble, K.H., T.O. Knight, R.D. Pope, and J.R. Williams. 1996. "Modeling Farm-Level Crop Insurance Demand with Panel Data." American Journal of Agricultural Economics 78(2): 439-47.

DellaVigna, S. 2007. Psychology and economics: Evidence from the field. National Bureau of Economic Research Working Papers, No. 12420, (C) 2007 by Stefano DellaVigna.

Du, X., H. Feng, and D.A. Hennessy. 2016. "Rationality of Choices in Subsidized Crop Insurance Markets." American Journal of Agricultural Economics 99(3): 732-756.

Eckles, D.L., and J.V. Wise. 2011. Prospect Theory and the Demand for Insurance. The Risk Theory Society, American Risk and Insurance Association (ARIA), Philadelphia, PA USA. Available at http://www.aria.org/rts/proceedings/2012/default.html (accessed September 2013).

Enjolras, G., and P. Sentis. 2011. "Crop Insurance Policies and Purchases in France." Agricultural Economics 42(4): 475-86.

Finger, R., and N. Lehmann. 2012. "The Influence of Direct Payments on Farmers' Hail Insurance Decisions." Agricultural Economics 43(3): 343-54.

Freund, C., and Ç. Özden. 2008. "Trade Policy and Loss Aversion." The American Economic Review 98(4): 1675-91.

Garrido Colmenero, A., and D. Zilberman. 2007. "Revisiting the Demand of Agricultural Insurance: The Case of Spain." Agricultural Finance Review 68(1): 43-66.

Goodwin, B.K. 1993. "An Empirical Analysis of the Demand for Multiple Peril Crop Insurance." American Journal of Agricultural Economics 75(2): 425-34.

Hwang, I.D. 2015. Prospect Theory and Insurance Demand. Available at SSRN 2586360.

Kahneman, D., and A. Tversky. 1979. "Prospect Theory: An Analysis of Decision Under Risk." Econometrica 47(2): 263-91.

Lefebvre, M., D. Nikolov, S. Gomez-y-Paloma, and M. Chopeva. 2014. "Determinants of Insurance Adoption among Bulgarian Farmers." Agricultural Finance Review 74(3): 326-47.

Mishra, A.K., and B.K. Goodwin. 2003. "Adoption of Crop Versus Revenue Insurance: A FarmLevel Analysis." Agricultural Finance Review 63(2): 143-55.

Niewuwoudt, W., and J.B. Bullock. 1985. The demand for crop insurance. Paper presented at 1985 Conference, August 26-September 4, 1985, Málaga, Spain.

Pennings, J.M., O. Isengildina-Massa, S.H. Irwin, P. Garcia, and D.L. Good. 2008. "Producers' complex Risk Management Choices." Agribusiness 24(1): 31-54.

Poon, K. 2013. "Risky Business: Factors Affecting Participation Rate of AgriStability." Presented at the AAEA \& CAES Joint Annual Meeting, Washington, DC. Available at https://ageconsearch.umn.edu/record/150978. DOI 10.22004/ag.econ.150978. 
Rabin, M. 1998. "Psychology and Economics." Journal of Economic Literature 36(1): 11-46.

Santeramo, F.G., B.K. Goodwin, F. Adinolfi, and F. Capitanio. 2016. "Farmer Participation, Entry and Exit Decisions in the Italian Crop Insurance Programme." Journal of Agricultural Economics 67(3): 639-657.

Sherrick, B.J., P.J. Barry, P.N. Ellinger, and G.D. Schnitkey. 2004. "Factors Influencing Farmers' Crop Insurance Decisions." American Journal of Agricultural Economics 86(1): 103-14.

Smith, V.H., and A.E. Baquet., 1996. "The Demand for Multiple Peril Crop Insurance: Evidence From Montana Wheat Farms." American Journal of Agricultural Economics 78(1): 189201.

Stiglitz, J.E. 1987. "Some Theoretical Aspects of Agricultural Policies." The World Bank Research Observer 2(1): 43-60.

Taylor, M.R., G.T. Tonsor, N.D. Paulson, B. Ellison, J. Coppess, and G.D. Schnitkey. 2017. "Is it Good to Have Options? The 2014 Farm Bill Program Decisions." Applied Economic Perspectives and Policy 39(4): 533-546.

Tversky, A., and D. Kahneman. 1992. "Advances in Prospect Theory: Cumulative Representation of Uncertainty." Journal of Risk and Uncertainty 5(4): 297-323.

Uzea, F., K. Poon, D. Sparling, and A. Weersink. 2014a. Substitutes versus Complements among Canadian Business Risk Management Programs. Paper presented at 2014 Agricultural and Applied Economics Association (AAEA) Annual Meeting, July 27-29, 2014, Minneapolis, Minnesota

Uzea, F., K. Poon, D. Sparling, and A. Weersink. 2014b. "Farm Support Payments and Risk Balancing: Implications for Financial Riskiness of Canadian Farms." Canadian Journal of Agricultural Economics/Revue Canadienne D'agroeconomie 62(4): 595-618.

Velandia, M., R.M. Rejesus, T.O. Knight, and B.J. Sherrick. 2009. 'Factors Affecting Farmers' Utilization of Agricltural Risk Management Tools: The Case of Crop Insurance, Forward Contracting, and Spreading Sales." Journal of Agricultural and Applied Economics 41 (01): 107-23. 
Appendix

Table A1. Number (Percentage) of Producer Participating in AgriStability by Year and Revenue Size, 2003-2013

\begin{tabular}{|c|c|c|c|c|c|}
\hline \multirow[b]{2}{*}{ Year } & \multicolumn{5}{|c|}{ Revenue Sales Class (\$ thousands) } \\
\hline & $>0 \&<10$ & $>10 \&<100$ & $>100 \&<250$ & $>\mathbf{2 5 0} \&<\mathbf{5 0 0}$ & $>\mathbf{5 0 0}$ \\
\hline 2003 & $546(64.4 \%)$ & $3,023(82.1 \%)$ & $826(92.9 \%)$ & $440(97.1 \%)$ & $357(96.5 \%)$ \\
\hline 2004 & $622(58.1 \%)$ & $2,855(80.0 \%)$ & $683(93.6 \%)$ & $370(96.9 \%)$ & $262(95.3 \%)$ \\
\hline 2005 & $412(48.3 \%)$ & $3,072(77.6 \%)$ & $712(90.7 \%)$ & $399(93.9 \%)$ & $327(96.2 \%)$ \\
\hline 2006 & $353(42.7 \%)$ & $2,584(69.4 \%)$ & $699(86.8 \%)$ & $395(90.8 \%)$ & $322(92.5 \%)$ \\
\hline 2007 & $344(36.36 \%)$ & $2,254(65.9 \%)$ & $647(85.5 \%)$ & $369(87.2 \%)$ & $325(90.8 \%)$ \\
\hline 2008 & $293(36.1 \%)$ & $1,986(61.3 \%)$ & $615(82.7 \%)$ & $332(85.4 \%)$ & $353(88.5 \%)$ \\
\hline 2009 & $252(30.2 \%)$ & $1,691(58.6 \%)$ & $507(78.2 \%)$ & $306(84.5 \%)$ & $301(87.3 \%)$ \\
\hline 2010 & $163(25.9 \%)$ & $1,499(56.2 \%)$ & $533(77.1 \%)$ & $288(84.0 \%)$ & 309 (85.8\%) \\
\hline 2011 & $78(16.6 \%)$ & $1,188(47.4 \%)$ & 496 (72.1\%) & 291 (79.7\%) & $313(81.5 \%)$ \\
\hline 2012 & $72(17.1 \%)$ & 958 (45.3\%) & $413(67.8 \%)$ & 239 (73.3\%) & $325(81.7 \%)$ \\
\hline 2013 & $53(14.4 \%)$ & $813(40.5 \%)$ & $349(61.3 \%)$ & $216(72.0 \%)$ & $314(76.6 \%)$ \\
\hline
\end{tabular}

